\title{
Prediksi Tarikan Pergerakan Akibat Pengembangan Kampus Universitas Palangka Raya
}

\section{Prediction of Trip Attraction Due to The Development of The Palangka Raya University Campus}

\author{
Ikbal Akbar Said ${ }^{1}$, Sutan Parasian Silitonga ${ }^{2}$, Desi Riani $^{3}$ \\ ${ }^{1}$ Jurusan Teknik Sipil, Fakultas Teknik, Universitas Palangka Raya, Jln. Yos Sudarso Palangka Raya. \\ Email : ikbalakbar17@gmail.com \\ ${ }^{2}$ Jurusan Teknik Sipil, Fakultas Teknik, Universitas Palangka Raya, Jln. Yos Sudarso Palangka Raya. \\ Email : sutanparasian@yahoo.com \\ ${ }^{3}$ Jurusan Teknik Sipil, Fakultas Teknik, Universitas Palangka Raya, Jln. Yos Sudarso Palangka Raya. \\ Email : desiriani@jts.upr.ac.id
}

\begin{abstract}
Abstrak
Secara kuantitatif, Universitas Palangka Raya telah mengalami peningkatan yang luar biasa selama satu dekade terakhir. Dengan demikian, banyaknya peningkatan kuantitas penduduk kampus tahun demi tahun sehingga dibutuhkan sistem pengaturan yang baik untuk masa depan. Penelitian ini bertujuan untuk memprediksi tarikan pergerakan yang terjadi pada kampus UPR dalam jangka sepuluh tahun kedepan. Metode yang digunakan yaitu analisis trend moment untuk mengetahui trend perkembangan jumlah mahasiswa. Sedangkan untuk jumlah dosen dan staff diprediksi menggunakan rasio terhadap jumlah mahasiswa. Kemudian tarikan pergerakan diprediksi berdasarkan hasil kuesioner presentase intensitas harian menuju kampus dan kebiasaan pemilihan moda menuju kampus saat ini. Dari hasil analisis data, didapat prediksi tarikan pergerakan pada tahun 2021 sampai 2030 yaitu berkisar antara 19222 sampai 29903 orang/hari atau 18376 sampai 28587 kendaraan perhari dengan komposisi pemilihan moda $2 \%$ pejalan kaki; $2,3 \%$ pengguna sepeda; $78,2 \%$ pengguna sepeda motor; dan $17,4 \%$ pengguna mobil.
\end{abstract}

Kata Kunci: Prediksi tarikan pergerakan; analisis trend moment; pemilihan moda

\begin{abstract}
Quantitatively, University of Palangka Raya has experienced tremendous improvement over the last decade. Thus, the number of campus residents increases year after year so that a good regulatory system is needed for the future. This study aims to predict the trip attraction that will occur on the UPR campus in the next 10 years. The method used is trend moment analysis to determine the trend of the development of the number of students. Meanwhile, the number of lecturers and staff is predicted using the ratio to the number of students. Then the trip pull is predicted based on the results of the questionnaire on the percentage of daily intensity to campus and the habit of choosing mode to go to campus. From the results of data analysis, it is found that the prediction of trip attraction in 2021 to 2030, which ranges from 19222 to 29903 people/day or 18376 to 28587 vehicles per day with a composition of $2 \%$ pedestrian mode selection; $2.3 \%$ of bicycle users; $78.2 \%$ of motorcycle users; and $17.4 \%$ car users.
\end{abstract}

Keywords: Prediction of trip attraction; trend moment analysis; moda choice 


\section{PENDAHULUAN}

Kampus Universitas Palangka Raya (UPR) merupakan satu-satunya universitas negeri yang ada di Provinsi Kalimantan Tengah. Sampai saat ini kampus Universitas Palangka Raya memiliki 8 fakultas yang terdiri dari 36 program studi $S-1,1$ program pascasarjana yang terdiri dari 11 program studi S-2 dan 1 program doktoral, sehingga kampus Universitas Palangka Raya merupakan salah satu yang cukup padat dan paling banyak diminati dikarenakan jumlah program studi yang jauh lebih banyak dibanding kampus lainnya yang berada di Kota Palangka Raya. Secara kuantitatif, UPR telah mengalami peningkatan yang luar biasa selama satu dekade terakhir. Jumlah gedung perkantoran dan perkuliahan serta sarana dan prasarana pendidikan terus meningkat dari tahun ke tahun. Jumlah dosen, karyawan dan mahasiswa yang sama-sama meningkat secara linier juga telah membuat rata-rata rasio dosen dan mahasiswa di universitas ini pada kondisi yang sangat ideal saat ini. Dengan semakin banyaknya peningkatan kuantitas penduduk kampus tahun demi tahun sehingga dibutuhkan sistem pengaturan yang baik untuk masa depan.

Dalam penulisan jurnal penelitian ini, peneliti ingin mengetahui berapa besar jumlah tarikan pergerakan yang akan terjadi akibat pengembangan kampus Universitas Palangka raya dalam jangka 10 tahun kedepan. Tarikan pergerakan diprediksi berdasarkan data yang ada saat ini dan yang telah berlalu yaitu menggunakan trend perkembangan jumlah mahasiswa, dosen dan staff kampus UPR. Selain itu, tarikan pergerakan diprediksi pula berdasarkan intensitas harian menuju kampus dan kebiasaan pemilihan moda menuju kampus oleh seluruh penduduk kampus Universitas Palangka Raya.

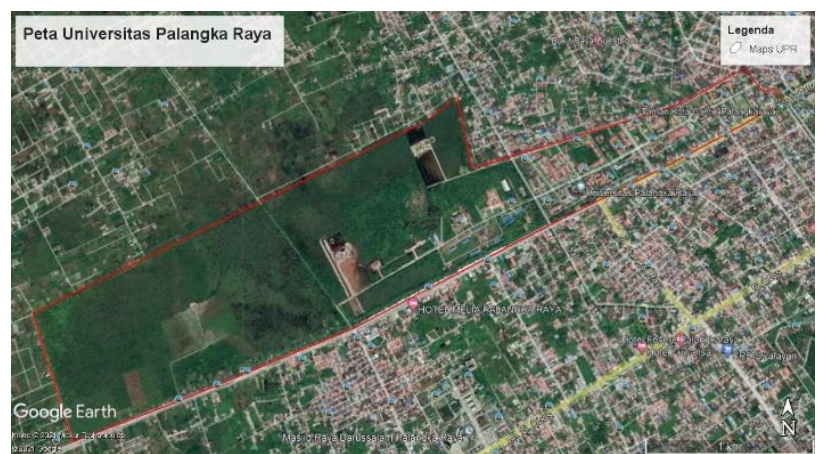

Gambar 1. Peta Kampus Universitas Palangka Raya Sumber: Google Earth Pro

\section{TINJAUAN PUSTAKA}

\section{Bangkitan dan Tarikan Pergerakan}

Menurut Tamin, Bangkitan pergerakan adalah tahapan permodelan yang memperkirakan jumlah pergerakan yang berasal dari suatu zona atau tata guna lahan dan jumlah pergerakan yang tertarik ke suatu tata guna lahan atau zona. Tarikan pergerakan adalah jumlah pergerakan yang tertarik ke suatu tata guna lahan atau zona (Tamin, 2000). Tarikan pergerakan tersebut berupa tarikan lalu lintas yang menuju atau tiba ke lokasi. Bangkitan dan tarikan pergerakan dapat ditunjukkan pada Gambar 1. berikut:

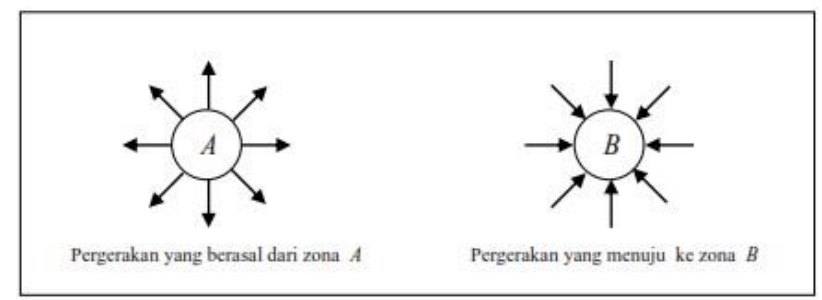

Gambar 2. Bangkitan dan Tarikan Pergerakan Sumber: Tamin, 2000.

\section{Prediksi}

Menurut Kamus Besar Bahasa Indonesia daring/online, prediksi adalah ramalan atau prakiraan. Peramalan adalah penggunaan data masa lalu dari sebuah variabel atau kumpulan variabel untuk mengestimasi nilainya di masa yang akan datang. Metode peramalan dapat dibagi dalam dua kategori utama, yaitu metode kualitatif dan metode kuantitatif. Metode kuantitatif dibutuhkan informasi masa lalu yang dikuantitatifkan dalam bentuk data numerik. Metode peramalan secara kuantitatif mendasarkan ramalannya pada metode statistika dan matematika. Terdapat dua model peramalan kuantitatif, yaitu model deret waktu (time series) dan model regresi (regression).

\section{Metode Trend Moment}

Dalam penelitian ini, metode prediksi/peramalan jumlah mahasiswa yang akan dilakukan yaitu model deret waktu (time series) yaitu analisis trend moment. Metode trend moment merupakan gabungan dari analisis statsitik berbentuk analisis trend dan metode moment. Trend Moment adalah metode peramalan Time-Series yang menyesuaikan garis trend pada sekumpulan data masa lalu dan kemudian diproyeksikan dalam garis untuk meramalkan masa depan untuk peramalan jangka pendek atau jangka panjang. Jika hal yang diteliti menunjukkan gejala kenaikan maka trend yang kita miliki menunjukkan rata-rata pertambahan, sering disebut trend positif, tetapi hal yang kita teliti menunjukkan gejala yang semakin berkurang maka trend yang kita miliki menunjukkan rata-rata penurunan atau disebut juga trend negatif (Subagyo, 2002). Kelebihan dari metode Trend Moment dibandingkan dengan metode lainnya terletak pada penggunaan parameter $\mathrm{X}$ yang dipakai, sehingga tidak ada perbedaan apakah data yang dipakai 
merupakan data historis berjumlah genap ataukah ganjil (Subagyo, 2002). Penerapan metode Trend Moment dapat di lakukan dengan menggunakan data historis dari satu variabel, adapun persamaan yang di gunakan dalam penyusunan dari metode ini menurut (Subagyo, 2002). Persamaan Trend dengan menggunakan metode Trend Moment pada persamaan [1].

$Y=a+b X$

Mencari nilai $a$ dan $b$ dan dengan cara penyelesaian menggunakan dua persamaan normal. Adapun persamaan untuk mencari nilai $b$ menurut (Subagyo, 2002) pada persamaan [2].

$b=\frac{\mathrm{n}\left(\sum \mathrm{XY}\right)-\left(\sum \mathrm{X}\right)\left(\sum \mathrm{Y}\right)}{\mathrm{n}\left(\sum X^{2}\right)-\left(\sum X\right)^{2}}$

Mencari nilai a menurut (Subagyo, 2002) pada persamaan [3].

$a=\frac{\left(\sum \mathrm{Y}\right)-\mathrm{b}\left(\sum \mathrm{X}\right)}{\mathrm{n}}$

Dimana:

Y : nilai variabel hasil peramalan.

a : bilangan konstanta.

$b \quad$ : slope atau kemiringan garis trend

X : indeks waktu $(0,1,2, \ldots . n)$.

$\mathrm{n}$ : banyaknya pengamatan.

\section{Rasio}

Rasio atau perbandingan adalah angka yang mewakili hubungan secara matematis antara suatu jumlah dengan jumlah lain. Dalam hal ini rasio digunakan untuk menghitung perbandingan antara jumlah dosen dan staff terhadap jumlah mahasiswa yang digunakan untuk memprediksi jumlah dosen dan staff dalam 10 tahun kedepan.

\section{Kuesioner}

Menurut Kamus Besar Bahasa Indonesia daring/online, kuesioner adalah alat riset atau survei yang terdiri atas serangkaian pertanyaan tertulis, bertujuan mendapatkan tanggapan dari kelompok orang terpilih melalui wawancara pribadi atau melalui pos. Dalam penelitian ini, kuesioner dilakukan menggunakan alat riset daring yaitu google form yang ditujukan kepada seluruh penduduk kampus UPR baik mahasiswa, dosen maupun staff.

Jumlah data yang ditentukan dengan metode sampling yang dikembangkan oleh Isaac dan Michael (Sugiyono, 2007) terhadap ukuran kecukupan sampel untuk tingkat kesalahan 5\% dan melaksanakan pengumpulannya dengan teknik snowball sampling.

Untuk lebih memudahkan perhitungan maka dapat ditentukan dengan Tabel Penentuan Jumlah Sampel Isaac \& Michael (terlampir) dengan tingkat akurasi 95\% (batas toleransi kesalahan adalah 5\%) kepada 20.772 orang (dibulatkan menjadi 21.000 orang) maka jumlah sampel yang dibutuhkan sebanyak 342 sampel.

\section{METODE PENELITIAN}

Penelitian ini dilakukan untuk memprediksi jumlah tarikan pergerakan pada kampus Universitas Palangka Raya dalam jangka 10 tahun kedepan. Adapun data yang diperlukan yaitu data primer dan data sekunder. Data primer adalah hasil kuesioner terhadap seluruh penduduk kampus UPR mengenai pemilihan moda sehari-hari menuju kampus dan intensitas mahasiswa menuju kampus dalam satu minggu. Sedangkan data sekunder yaitu data jumlah mahasiswa dalam 5 tahun terakhir (2016-2020) dan jumlah dosen (tenaga pendidik) dan staff (tenaga kependidikan) pada tahun 2020.

Analisis data yang dilakukan yaitu memprediksi jumlah mahasiswa dalam 10 tahun kedepan menggunakan metode trend moment, dan jumlah dosen serta staff menggunakan rasio. Kemudian tarikan pergerakan diperkirakan berdasarkan ratarata intensitas penduduk kampus menuju kampus dan komposisi kebiasaan pemilihan moda menuju kampus (Hasil Kuesioner).

\section{Pengumpulan Data Sekunder}

Tabel 1. Jumlah Mahasiswa, Dosen dan Staff UPR

\begin{tabular}{cccc}
\hline Tahun & Mahasiswa & Dosen & Staff \\
\hline 2016 & 15215 & - & - \\
\hline 2017 & 17002 & - & - \\
\hline 2018 & 19458 & - & - \\
\hline 2019 & 19884 & - & - \\
\hline 2020 & 20772 & 784 & 214 \\
\hline
\end{tabular}

\section{Pengumpulan Data Primer (Hasil Kuesioner)}

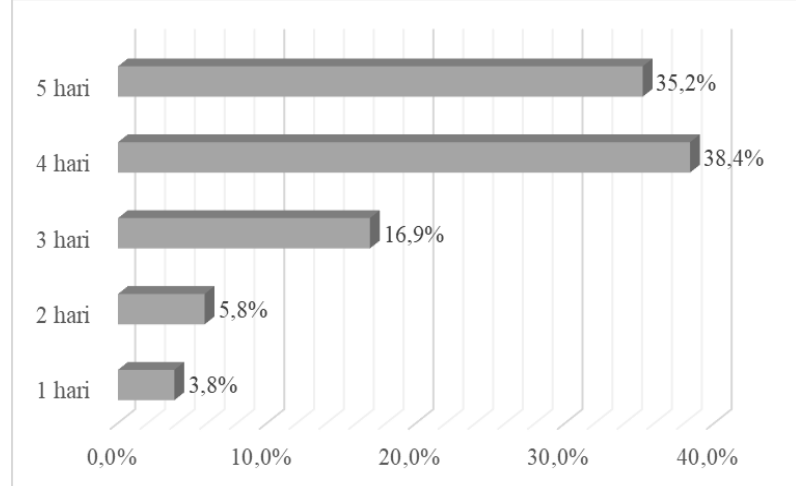

Gambar 3. Presentase Intensitas Mahasiswa menuju 
Kampus dalam Seminggu

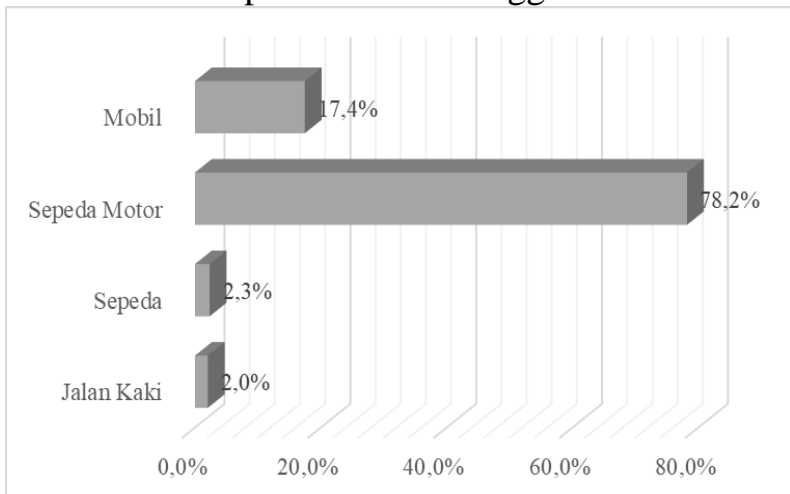

Gambar 4. Presentase Komposisi Kebiasaan Pemilihan Moda menuju Kampus

\section{HASIL DAN PEMBAHASAN}

Prediksi Jumlah Mahasiswa

Tabel 2. Perhitungan Trend Moment

\begin{tabular}{rcccc}
\hline Tahun & $\begin{array}{c}\text { Periode } \\
(\mathrm{X})\end{array}$ & $\begin{array}{c}\text { Jumlah } \\
\text { Mahasiswa } \\
(\mathrm{Y})\end{array}$ & $\mathrm{XY}$ & $\mathrm{X}^{\wedge} 2$ \\
\hline 2016 & 0 & 15215 & 0 & 0 \\
2017 & 1 & 17002 & 17002 & 1 \\
2018 & 2 & 19458 & 38916 & 4 \\
2019 & 3 & 19884 & 59652 & 9 \\
2020 & 4 & 20772 & 83088 & 16 \\
& $\sum \quad 10$ & 92331 & 198658 & 30 \\
$b=$ & $\frac{\mathrm{n}\left(\sum \mathrm{XY}\right)-\left(\sum \mathrm{X}\right)\left(\sum \mathrm{Y}\right)}{\mathrm{n}\left(\sum X^{2}\right)-\left(\sum X\right)^{2}}=\frac{5(198658)-(10)(92331)}{5(30)-(10)^{2}}$ \\
$b$ & $=1399,6$ \\
$a$ & $=\frac{\left(\sum \mathrm{Y}\right)-\mathrm{b}\left(\sum \mathrm{X}\right)}{\mathrm{n}}=\frac{(92331)-(1399,6)(10)}{2}$ \\
$a$ & $=15667$ \\
$Y$ & $=a+b X$ \\
$Y$ & $=1399,6 X+15667$
\end{tabular}

\section{Rasio Jumlah Dosen dan Staff Terhadap Jumlah Mahasiswa}

Tabel 3. Rasio Jumlah Dosen

\begin{tabular}{ccc}
\hline $\begin{array}{c}\text { Jumlah } \\
\text { Dosen 2020 }\end{array}$ & $\begin{array}{c}\text { Jumlah } \\
\text { Mahasiswa 2020 }\end{array}$ & Rasio \\
\hline 784 & 20772 & $1: 26,49$ \\
\hline \multicolumn{3}{c}{ Tabel 4. Rasio Jumlah Staff } \\
\hline $\begin{array}{c}\text { Jumlah } \\
\text { Staff 2020 }\end{array}$ & $\begin{array}{c}\text { Jumlah } \\
\text { Mahasiswa 2020 }\end{array}$ & Rasio \\
\hline 214 & 20772 & $1: 97,06$ \\
\hline
\end{tabular}

\section{Proyeksi Jumlah Mahasiswa, Dosen dan Staff}

Proyeksi jumlah mahasiswa, dosen dan staff merupakan gambaran tentang jumlah/kuantitas dari mahasiswa, dosen dan staff dalam 10 tahun kedepan. Prediksi jumlah mahasiswa berdasarkan hasil dari analisis trend moment pada Tabel 2. Yaitu dengan memasukkan nilai periode lanjutan $(X=5,6,7,8,9$, $10,11,12,13,14)$ pada persamaan Y. Kemudian jumlah dosen dan staff dihitung dengan mengalikan jumlah mahasiswa dengan rasio dosen dan staff terhadap jumlah mahasiswa. Hasil dari perhitungan tersebut dapat ditunjukkan pada Tabel 5. Berikut:

Tabel 5. Proyeksi Jumlah Mahasiswa, Dosen dan Staff

\begin{tabular}{cccc}
\multicolumn{4}{c}{ Staff } \\
\hline \multirow{2}{*}{ Tahun } & $\begin{array}{c}\text { Jumlah } \\
\text { Mahasiswa }\end{array}$ & $\begin{array}{c}\text { Jumlah } \\
\text { Dosen }\end{array}$ & $\begin{array}{c}\text { Jumlah } \\
\text { Staff }\end{array}$ \\
\hline 2021 & 22665 & 864 & 234 \\
\hline 2022 & 24065 & 908 & 248 \\
\hline 2023 & 25464 & 961 & 262 \\
\hline 2024 & 26864 & 1014 & 277 \\
\hline 2025 & 28263 & 1067 & 291 \\
\hline 2026 & 29663 & 1120 & 306 \\
\hline 2027 & 31063 & 1173 & 320 \\
\hline 2028 & 32462 & 1225 & 334 \\
\hline 2029 & 33862 & 1278 & 349 \\
\hline 2030 & 35261 & 1331 & 363 \\
\hline
\end{tabular}

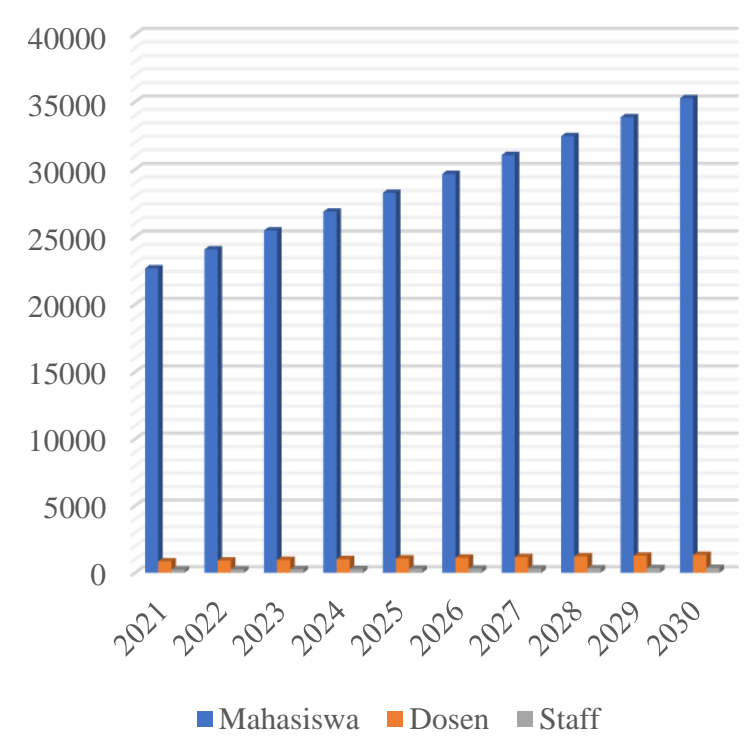

Gambar 5. Diagram Proyeksi Penduduk Kampus UPR

Prediksi Tarikan Pergerakan

Prediksi tarikan pergerakan dihitung berdasarkan hasil kuesioner/survei intensitas harian menuju kampus dalam seminggu (hari kerja). Untuk mahasiswa didapat rata-rata intensitas menuju kampus yaitu 4 hari dalam seminggu (5 hari kerja), sedangkan untuk intensitas dosen dan staff menuju kampus yaitu tiap hari (5 hari). Sehingga prediksi tarikan perjalaan harian dihitung dengan jumlah mahasiswa dikali 4 (hari) dibagi dengan 5 (hari kerja dalam seminggu) kemudian ditambahkan dengan jumlah dosen dan staff. Kemudian prediksi tarikan harian dihitung berdasarkan presentase pemilihan moda harian oleh penduduk kampus UPR, sehingga didapat jumlah harian pejalan kaki, pengguna 
sepeda, sepeda motor, serta mobil. Sedangkan prediksi tarikan dengan satuan kendaraan perhari didapat dari menjumlahkan pengguna harian kendaraan bermotor yaitu sepeda motor dan mobil sehingga didapat prediksi tarikan kendaraan perhari.

Tabel 6. Prediksi Total Tarikan Pergerakan

\begin{tabular}{|c|c|c|c|c|}
\hline \multirow{2}{*}{ Tahun } & \multicolumn{3}{|c|}{ Penduduk Kampus } & \multirow{2}{*}{$\begin{array}{c}\text { Prediksi } \\
\text { Tarikan } \\
\text { Harian } \\
\text { (orang/hari) }\end{array}$} \\
\hline & MHS & Dosen & Staff & \\
\hline 2021 & 22665 & 856 & 234 & 19222 \\
\hline 2022 & 24065 & 908 & 248 & 20408 \\
\hline 2023 & 25464 & 961 & 262 & 21594 \\
\hline 2024 & 26864 & 1014 & 277 & 22782 \\
\hline 2025 & 28263 & 1067 & 291 & 23968 \\
\hline 2026 & 29663 & 1120 & 306 & 25156 \\
\hline 2027 & 31063 & 1173 & 320 & 26343 \\
\hline 2028 & 32462 & 1225 & 334 & 27529 \\
\hline 2029 & 33862 & 1278 & 349 & 28717 \\
\hline 2030 & 35261 & 1331 & 363 & 29903 \\
\hline
\end{tabular}

Tabel 7. Prediksi Total Kendaraan Perhari

\begin{tabular}{ccccc}
\hline Tahun & $\begin{array}{c}\text { Pejalan } \\
\text { Kaki } \\
(2 \%)\end{array}$ & $\begin{array}{c}\text { Sepeda } \\
(2,3 \%)\end{array}$ & $\begin{array}{c}\text { Sepeda } \\
\text { Motor } \\
(78,2 \%)\end{array}$ & $\begin{array}{c}\text { Mobil } \\
(17,4 \%)\end{array}$ \\
\hline 2021 & 384 & 18376 & 15032 & 3345 \\
\hline 2022 & 408 & 19510 & 15959 & 3551 \\
\hline 2023 & 432 & 20644 & 16887 & 3757 \\
\hline 2024 & 456 & 21780 & 17816 & 3964 \\
\hline 2025 & 479 & 22914 & 18743 & 4171 \\
\hline 2026 & 503 & 24050 & 19672 & 4377 \\
\hline 2027 & 527 & 25184 & 20601 & 4584 \\
\hline 2028 & 551 & 26317 & 21527 & 4790 \\
\hline 2029 & 574 & 27453 & 22456 & 4997 \\
\hline 2030 & 598 & 28587 & 23384 & 5203 \\
\hline
\end{tabular}

Tabel 8. Rekapitulasi Total Prediksi Tarikan

\begin{tabular}{ccc}
\hline Tahun & $\begin{array}{c}\text { Prediksi Tarikan } \\
\text { Harian } \\
\text { (orang/hari) }\end{array}$ & $\begin{array}{c}\text { Prediksi Tarikan } \\
\text { kendaraan } \\
\text { (kendaraan/hari) }\end{array}$ \\
\hline 2021 & 19222 & 18376 \\
\hline 2022 & 20408 & 19510 \\
\hline 2023 & 21594 & 20644 \\
\hline 2024 & 22782 & 21780 \\
\hline 2025 & 23968 & 22914 \\
\hline 2026 & 25156 & 24050 \\
\hline 2027 & 26343 & 25184 \\
\hline 2028 & 27529 & 26317 \\
\hline 2029 & 28717 & 27453 \\
\hline 2030 & 29903 & 28587 \\
\hline
\end{tabular}

\section{SIMPULAN}

Bedasarkan hasil analisis data, dapat ditentukan kesimpulan yaitu sebagai berikut:

1. Prediksi tarikan pergerakan pada kampus UPR tahun 2021 yaitu 19222 orang/hari atau 18376 kendaraan/hari.

2. Prediksi tarikan pergerakan pada kampus UPR tahun 2022 yaitu 20408 orang/hari atau 19510 kendaraan/hari.

3. Prediksi tarikan pergerakan pada kampus UPR tahun 2023 yaitu 21594 orang/hari atau 20644 kendaraan/hari.

4. Prediksi tarikan pergerakan pada kampus UPR tahun 2024 yaitu 22782 orang/hari atau 21780 kendaraan/hari.

5. Prediksi tarikan pergerakan pada kampus UPR tahun 2025 yaitu 23968 orang/hari atau 22914 kendaraan/hari.

6. Prediksi tarikan pergerakan pada kampus UPR tahun 2026 yaitu 25156 orang/hari atau 24050 kendaraan/hari.

7. Prediksi tarikan pergerakan pada kampus UPR tahun 2027 yaitu 26343 orang/hari atau 25184 kendaraan/hari.

8. Prediksi tarikan pergerakan pada kampus UPR tahun 2028 yaitu 27529 orang/hari atau 26317 kendaraan/hari.

9. Prediksi tarikan pergerakan pada kampus UPR tahun 2029 yaitu 28717 orang/hari atau 27453 kendaraan/hari..

10.Prediksi tarikan pergerakan pada kampus UPR tahun 2030 yaitu 29903 orang/hari atau 28587 kendaraan/hari.

\section{REFERENSI}

KBBI Daring, 2021. Kamus Besar Bahasa Indonesia. [Daring] Tersedia pada: https://kbbi.kemdikbud.go.id/ [Diakses pada 30 November 2021].

PDDikti, 2021. Pangkalan Data Pendidikan Tinggi. [Daring] Tersedia pada: https://pddikti.kemdikbud.go.id/ [Diakses pada 25-29 Oktober 2021].

Subagyo. 2002. Forecasting: Konsep dan Aplikasi. Yogyakarta: BPFE.

Sugiyono, 2007. Metode Penelitian Bisnis. Bandung: Penerbit Alfabeta.

Susanti, A., Wibisono, R. E., \& Kusuma, E. A. 2020. Model Bangkitan Perjalanan Penduduk Perumahan Pinggiran Kota (Studi Kasus Perumahan Bukit Bambe Driyorejo Gresik). Publikasi Riset Orientasi Teknik Sipil (Proteksi), 2(2), 55-66.

Tamin, O. Z. 2000. Perencanaan dan Pemodelan Transportasi. Edisi Kedua. Bandung: Penerbit ITB.

Proteksi/Desember 2021 Volume 3 No. 2 
Wibisono, R. E., Herijanto, W., \& Widyastuti, H. 2014. Studi Pemodelan Trip Distibution Penumpang Penyeberangan Kapal Ferry di
Pelabuhan Ujung Surabaya-Kamal Setelah Beroperasinya Jembatan Suramadu. In Prosiding Seminar Nasional Te ni Sipil X2014, hal (pp. 301-310). 